\title{
Evaluating the effectiveness of mergers and acquisitions for agribusiness companies
}

\author{
Igor Aleksandrov ${ }^{1 *}$, Marina Fedorova ${ }^{2}$, and Aleksey Parshukov ${ }^{1}$ \\ ${ }^{1}$ Peter the Great St.Petersburg Polytechnic University, Polytechnicheskaya 29, 195251, St. \\ Petersburg, Russia \\ ${ }^{2}$ Petrozavodsk State University, Lenina 33, 185910, Petrozavodsk, Russia
}

\begin{abstract}
This research is aimed at improving the efficiency of evaluating mergers and acquisitions for companies in the agro-industrial complex. When evaluating these transactions, it is necessary to take into account their impact on the environment. The paper analyzes the problems associated with the evaluation of these transactions and identifies ways to improve the evaluation methods. The authors ' approach to evaluating acquisitions based on the assessment of changes in the company's potential is intended to improve the accuracy of the assessment and reduce the risks of revaluation of discounted cash flow from acquisitions. Assessment of potential changes as a result of the implementation of integration projects will allow assessing the economic impact of takeover options, taking into account the environmental consequences for the territory. The proposed approach is aimed at more accurate accounting for changes in intellectual capital of the combined company as a result of integration. Rationalization of the evaluation of the effectiveness of acquisitions will allow owners and management of agro-industrial companies to reduce the risks of making ineffective decisions.
\end{abstract}

\section{Introduction}

The agro-industrial complex of Russia has a number of systemic problems that prevent the country from taking a well-deserved share in the total world food production. This industry has significant potential and can become a source of development of vast territories of Russia. The deterioration of political and economic relations with Western European countries affected all sectors of the Russian economy. The agricultural sector is no exception. On the one hand, Russian companies have been able to take a larger share in the domestic market as a result of reduced competitive pressure from foreign companies. On the other hand, the crisis has made it difficult for Russian companies to use relatively easily available and cheap foreign debt capital. Many declared investment transactions were suspended or canceled due to general uncertainty.

Currently, Integration transactions are often the only way to raise funds to refinance or support planned projects. In recent years, the number of mergers and acquisitions in Russia

\footnotetext{
* Corresponding author: a7830298@gmail.com
} 
has been constantly growing [1]. This research is aimed at improving the efficiency of evaluating mergers and acquisitions for companies in the agro-industrial complex.

Strategic management is aimed at forming a strategic concept of survival and development to ensure sustainable growth of the company's potential. The problem of integration can be considered as an important problem of strategic management of companies in the agro-industrial complex of the Russian Federation

\section{Literature Review}

Growth and change in the structure of companies is an integral part of the life cycle, so mergers and acquisitions remain an essential part of the modern economy and are an important element of market regulation [2]. Acquisitions and mergers are an important element of the company's strategic management, which is carried out in order to increase its potential and ensure its strategic invulnerability[3]. Along with purely market-based acquisitions and mergers, integration processes carried out in the state and regional interests, with the active participation of Federal and regional government bodies, deserve attention [4]. The state may be interested in the development of promising sectors of the economy [5], the concentration and development of technological areas of the defense industry, etc.

Successful management of the company implies the ability to respond quickly to possible changes in the economic, political, legal and social factors of the external environment [6]. Mergers and acquisitions of companies are one of the forms of reorganization as a response to these changes [7]. Practice shows that most transactions related to mergers and acquisitions are unsuccessful for the companies that initiate them [8]. The purpose of buying a business or controlling interest in it is to generate profit, return on investment, but not the fact of establishing control. Practice shows that it is for the fact of control that buyers often pay amounts that are incommensurable with the future income from the combination. As a rule, the analysis of integration effectiveness begins with the forecast of future cash flows of companies participating in integration [9]. This forecast includes any assumption of increased revenue or reduced costs resulting from a merger or acquisition, then these amounts are discounted and the results are compared with the transaction price. The expected gain from an acquisition is determined by calculating the difference between the discounted cash flow of the acquired company, including the benefits of a merger or acquisition, and the cash required to implement the integration. If the present value of the expected cash flow from the integration exceeds the price requested by the seller (or which must be paid to collect the necessary stock in the market), the acquiring company can make a purchase.

Thus, to analyze the effectiveness of mergers or acquisitions of companies, it is necessary to:

- $\quad$ cash flow forecasting;

- $\quad$ determining the level of the discount rate to assess the projected cash flow;

- valuation of the acquired company;

- data analysis.

The approach discussed above does not always produce objective results. Even an experienced analyst can make serious mistakes in assessing the company's value [10]. The expected net benefit may be positive only because of an overly optimistic estimate of the company's future cash flows [11]. It is necessary to offer an approach to the assessment of integration transactions, the use of which will reduce the risks of erroneous decisions.

Recently, many researchers have made attempts to analyze the potential and its components [12]. This raises the question of what to call the potential of a company, region, country, and how to make a quantitative and qualitative assessment of it. 


\section{Methodology}

The potential of an agro-industrial company forms the market value of this subject, which can be determined directly by the market or analytically. By the potential of an organization, we will understand its ability to generate stable cash flows [13].

The potential of an economic entity acts both as a carrier and as a measure of its capabilities and is the main target factor of strategic management. The company's potential includes resources and conditions for reproducing these resources. To solve the problem of evaluating an integration transaction, it is necessary to build an economic and mathematical model that describes the assessment of potential changes as a result of integration. In [13], the authors proposed to calculate the potential in value terms as the sum of the net accumulated values of the most preferred projects and the potential residual value of the company (PRV) after the completion of projects. The potential residual value (PRV) is calculated as the product of the value of tangible assets and the asset efficiency coefficient. This is done for a more complete accounting of the company's intellectual capital after the end of projects. It is proposed to allocate the following groups of projects for the evaluated company:

- $\quad$ group M1 (active projects) - traditional projects of the company $(\mathrm{m} 11, \ldots, \mathrm{m} 1 \mathrm{w})$, implemented at the time of evaluation;

- $\quad$ group M2 (planned projects) -the company's projects $(\mathrm{m} 21, \ldots, \mathrm{m} 2 \mathrm{q})$ that are planned for implementation;

- $\quad$ group M3 (potential projects)- projects $(\mathrm{m} 31, \ldots, \mathrm{m} 3 \mathrm{~g})$ can be implemented by the company.

Given the above, the formula for evaluating the potential of company $\mathrm{k}$ will look like this:

$$
\mathrm{P}^{\mathrm{k}}=\sum_{\mathrm{i}=1}^{\mathrm{w}} \mathrm{NPV}\left(\mathrm{m}_{1 \mathrm{i}}\right)+\sum_{\mathrm{j}=1}^{\mathrm{q}} \mathrm{NPV}\left(\mathrm{m}_{2 \mathrm{j}}\right)+\sum_{\mathrm{t}=1}^{\mathrm{g}} \mathrm{NPV}\left(\mathrm{m}_{3 \mathrm{t}}\right)+\eta^{*} \mathrm{~A}_{1} \mathrm{k}^{\mathrm{k}} \frac{\sum_{\mathrm{i}=1}^{\mathrm{w}} \mathrm{NPV}\left(\mathrm{m}_{1 \mathrm{i}}\right)+\sum_{\mathrm{j}=1}^{\mathrm{q}} \mathrm{NPV}\left(\mathrm{m}_{2 \mathrm{j}}\right)+\sum_{\mathrm{t}=1}^{\mathrm{g}} \mathrm{NPV}\left(\mathrm{m}_{3 \mathrm{t}}\right)}{\mathrm{A}^{\mathrm{k}}}
$$

where $P^{k}$-the company's potential; $\sum_{i=1}^{w} N P V\left(m_{1 i}\right), \sum_{j=1}^{q} N P V\left(m_{2 j}\right)$ and $\sum_{t=1}^{g} N P V\left(m_{3 t}\right)-$ the sum of the net present values $\mathrm{w}$ of the company's current, $\mathrm{q}$ planned and g potential projects; $A^{k}$ - the value of net assets at the time of valuation; $\eta$ - an adjustment coefficient that takes into account the preservation of the company's business profile after the end of the forecast period $(0 \leq \eta \leq 1) ; A_{1}^{k}-$ the discounted value of net assets at the end of the planning period (excluding cash).

If the ratio of the sum of the net present values of the projects of the business entity to the net assets at the end of the planning period is less than one, this ratio is taken as one when calculating the potential.

Cash flows from projects in groups M1, M2, and M3 are discounted at rates that take into account the cost of capital, the risk of each project, and possible inflation.

Formula (1) allows you to analyze the company's potential in the context of market value. The main restrictions on this formula are related to the assumption that the considered set of projects (M1, M2, M3) should be the most (sufficiently) preferred for this business entity. Since the above model allows you to evaluate all components of potential in an analytical form (financial, technological, intellectual, organizational, psychological, image, etc.), it can be used in principle to evaluate the effectiveness of mergers and acquisitions. 


\section{Research}

The authors points out important to reveal the management problems which influence the processes of mergers and acquisitions most of all.

To reveal the rate of importance, the authors [15] interviewed the experts. The experts proposed possible reasons of integrations processes' failures. They also proposed to estimate those problems of integrations processes according their rate of importance. The relevance of scale is the following one, 1 point - the most important problem, 5 points - the least important problem.

The results of the interview are shown in the Table 1. We argue that the most important problem is unobjective evaluation of mergers and acquisitions.

Table 1. Importance of problems mergers and acquisitions.

\begin{tabular}{|c|c|c|c|c|c|}
\hline & \multicolumn{5}{|c|}{ Problems of integration processes } \\
\hline & 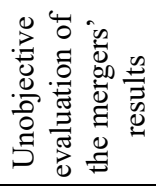 & 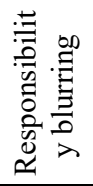 & 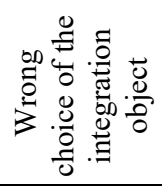 & 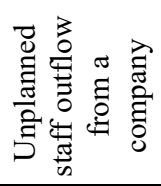 & 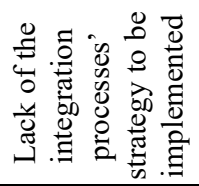 \\
\hline Expert 1 & 1 & 5 & 4 & 2 & 3 \\
\hline Expert 2 & 1 & 4 & 2 & 5 & 3 \\
\hline Expert 3 & 1 & 5 & 2 & 3 & 4 \\
\hline Expert 4 & 2 & 4 & 3 & 5 & 1 \\
\hline Expert 5 & 1 & 5 & 3 & 2 & 4 \\
\hline Expert 6 & 1 & 2 & 3 & 4 & 5 \\
\hline $\begin{array}{l}\text { Total amount } \\
\text { of points } \\
\text { assigned to a } \\
\text { problem }\end{array}$ & 7 & 25 & 17 & 21 & 20 \\
\hline $\begin{array}{c}\text { Rate of } \\
\text { importance }\end{array}$ & 1 & 5 & 2 & 4 & 3 \\
\hline
\end{tabular}

The authors propose to evaluate the effectiveness of the proposed takeover transaction by evaluating the change in the potential of the company that initiates the takeover. We will call this company the base company. The company that can be attached to the base company will be called the target company.

A takeover deal will be beneficial to the underlying company if the transaction increases the potential of the underlying company. To identify changes in the potential of the underlying company, you need to measure the potential of the underlying company before and after the planned takeover of the target company.

Based on the potential assessment model, a model for evaluating the effectiveness of company acquisition processes can be built.

To assess the potential of the base company, we propose to develop the mechanism proposed by the authors [13] for evaluating the company's potential.

The following project groups are considered when evaluating the potential of the base structure without a takeover of the target company:

- $\quad$ group M1 (active projects) - traditional projects of the basic structure $(\mathrm{m} 11, \ldots, \mathrm{m} 1 \mathrm{w})$, implemented at the time of evaluation;

- $\quad$ M2 group (planned projects) -projects of the basic structure $(\mathrm{m} 21, \ldots, \mathrm{m} 2 \mathrm{q})$ planned for implementation;

- $\quad$ M3 group (potential projects)- projects $(\mathrm{m} 31, \ldots, \mathrm{m} 3 \mathrm{~g})$ possible for implementation by the basic structure. 
For the combined structure (as a result of the takeover), the project groups will be as follows:

- $\quad$ group N1 (active projects) - traditional projects of the basic structure and company goals $(\mathrm{n} 11, \ldots, \mathrm{n} 1 \mathrm{v})$ that are planned for implementation even after the merger (with possible increase in efficiency due to synergy);

- $\quad$ group N2 (planned projects) - projects of the basic structure and company goals $(\mathrm{n} 21, \ldots, \mathrm{n} 2 \mathrm{p})$ that were planned before the merger and remain possible after it (with possible increase in efficiency due to synergy);

- $\quad$ group N3 (potential projects)- projects (n31,.., n3h) that can be implemented if combined.

$$
\begin{aligned}
& \Delta \mathrm{P}_{\mathrm{n}}{ }^{\mathrm{k}}=\sum_{\mathrm{e}=1}^{\mathrm{v}} \mathrm{NPV}\left(\mathrm{n}_{1 \mathrm{e}}\right)+\sum_{\mathrm{b}=1}^{\mathrm{p}} \mathrm{NPV}\left(\mathrm{n}_{2 \mathrm{~b}}\right)+\sum_{\mathrm{c}=1}^{\mathrm{h}} \mathrm{NPV}\left(\mathrm{n}_{3 \mathrm{c}}\right)+ \\
& +A_{1}{ }^{k+l} * \eta_{1} * \frac{\sum_{e=1}^{v} \operatorname{NPV}\left(n_{1 e}\right)+\sum_{b=1}^{p} N P V\left(n_{2 b}\right)+\sum_{c=1}^{h} N P V\left(n_{3 c}\right)}{A^{k+l}}- \\
& -\sum_{\mathrm{i}=1}^{\mathrm{w}} \mathrm{NPV}\left(\mathrm{m}_{1 \mathrm{i}}\right)-\sum_{\mathrm{j}=1}^{\mathrm{q}} \mathrm{NPV}\left(\mathrm{m}_{2 \mathrm{j}}\right)-\sum_{\mathrm{t}=1}^{\mathrm{g}} \mathrm{NPV}\left(\mathrm{m}_{3 \mathrm{t}}\right)- \\
& -\mathrm{A}_{1}{ }^{\mathrm{k} *} \eta_{2} * \frac{\sum_{\mathrm{i}=1}^{\mathrm{w}} \operatorname{NPV}\left(\mathrm{m}_{1 \mathrm{i}}\right)+\sum_{\mathrm{j}=1}^{\mathrm{q}} \mathrm{NPV}\left(\mathrm{m}_{2 \mathrm{j}}\right)+\sum_{\mathrm{t}=1}^{\mathrm{g}} \mathrm{NPV}\left(\mathrm{m}_{3 \mathrm{t}}\right)}{\mathrm{A}^{\mathrm{k}}}
\end{aligned}
$$

where $\Delta \mathrm{P}_{\mathrm{n}}{ }^{\mathrm{k}}$ - the increment of the capacity of the basic structure of the takeover of the target company; $\sum_{\mathrm{e}=1}^{\mathrm{v}} \mathrm{NPV}\left(\mathrm{n}_{1 \mathrm{e}}\right), \sum_{\mathrm{b}=1}^{\mathrm{p}} \mathrm{NPV}\left(\mathrm{n}_{2 \mathrm{~b}}\right)$ and $\sum_{\mathrm{c}=1}^{\mathrm{h}} \mathrm{NPV}\left(\mathrm{m}_{3 \mathrm{c}}\right)$-the sum of the net present value of existing $\mathrm{v}, \mathrm{p} \mathrm{h}$ planned and potential projects of the joint structure; $\sum_{\mathrm{i}=1}^{\mathrm{w}} \mathrm{NPV}\left(\mathrm{m}_{1 \mathrm{i}}\right), \sum_{\mathrm{j}=1}^{\mathrm{q}} \mathrm{NPV}\left(\mathrm{m}_{2 \mathrm{j}}\right)$ and $\sum_{\mathrm{t}=1}^{\mathrm{g}} \mathrm{NPV}\left(\mathrm{m}_{3 \mathrm{t}}\right)-$ the sum of the net present value $\mathrm{w}$ active, $\mathrm{q} g$ planned and potential projects of the basic structure; $\mathrm{A}_{1}^{\mathrm{k}+\mathrm{l}}$ - the discounted net asset value of the combined company at the end of the planning period (excluding cash); $\mathrm{A}^{\mathrm{k}+\mathrm{l}}$-the value of the net assets of the combined company at the time of evaluation; $\mathrm{A}_{1}^{\mathrm{k}}-$ the discounted net asset value of the underlying structure (excluding cash) at the end of the planning period; $\mathrm{A}^{\mathrm{k}}$-the net asset value of the underlying structure at the time of valuation; $\eta_{1}$ and $\eta_{2}$-correction factors that take into account the preservation of the combined company's business profile and the underlying structure after the end of the forecast period.

Cash flows from projects in groups M1, M2, M3, N1, N2, N3 are discounted at rates that take into account the cost of capital, the risk of each project and possible inflation.

\section{Discussion}

As already noted, the main problem of evaluating integration transactions is an unreliable assessment of their planned results [14]. Most errors are caused by the revaluation of planned cash flows and insufficient accounting of integration transaction costs. An important problem is a lack of accounting for changes in the intellectual capital of the combined company as a result of mergers and acquisitions [15]. On the one hand, traditional methods of evaluating companies do not accurately predict the cost of the intellectual capital of organizations. An assessment of the effectiveness of an integration transaction-based only on an assessment of future cash flows may lead to an underestimation of the level of intellectual capital of the merging companies. On the other hand, Intellectual capital can quickly become worthless as a result of mistakes in the pooling process. This is often due to the depreciation of human capital caused by the departure of key employees or the destruction of social ties in teams. 
The proposed approach to assessing acquisitions based on the assessment of potential changes is designed to reduce the risks of revaluation of discounted cash flow from acquisitions. This is done by dividing the cash flow into flows from three types of projects (current, planned, and potential) and critically analyzing the risks of each project. The proposed approach also aims to more accurately account for changes in the intellectual capital of the combined company as a result of integration.

\section{Conclusion}

Assessment of potential changes as a result of the implementation of integration projects will allow evaluating the effectiveness of projects for the long-term development of the agro-industrial complex. The use of such an indicator of effective absorption of companies as the change in potential will allow us to take into account not only the economic, but also the environmental consequences for the territory of the proposed integration projects.

The proposed approach to assessing acquisitions based on the assessment of potential changes is designed to reduce the risks of revaluation of discounted cash flow from acquisitions by critically analyzing the risks of each project. The proposed approach is aimed at more accurately accounting for changes in the intellectual capital of the combined company as a result of integration. Assessment of potential changes resulting from the implementation of new investment projects will allow evaluating the effectiveness of projects for the long-term development of the agro-industrial complex. Rationalization of evaluating the effectiveness of new projects will allow owners and management to reduce the risks of making ineffective decisions.

\section{References}

1. A Bril., O Kalinina,. A Kankovskaya,. V Vilken, Operational risk management in financing environmental activities and personnel management projects, E3S Web of Conferences, 110, 02018 (2019) DOI: 10.1051/e3sconf/201911002018

2. H. Kaila, F. Tarp, Can the Internet improve agricultural production, Evidence from Viet Nam, Agricultural Economics, 50, 675-91 (2019) DOI: 10.1111/agec.12517

3. O. Rasskazova, O. Kalinina, E. Zotova, Modern transformation of the production structure and its impact on the content of labor and the requirements for the skills and abilities of workers, MATEC Web of Conferences , 170 , 01041 (2018) DOI: https://doi.org/10.1051/matecconf/201817001041

4. V. Plotnikov, E. Gorin, O. Pirogova, The algorithms for the environmental finance based on adjusted present value models, E3S Web of Conferences, 91, 08021 (2019), DOI https://doi.org/10.1051/e3sconf/20199108021

5. D.O. Strebkov, A.V. Shevchuk, M.O. Spirina, Self-Employment In The Remote Work Market: Diffusion In Innovative Labor Practice, The Monitoring, 6, 89-106 (2016) DOI: 10.14515/monitoring.2016.6.06.

6. T. A. Masron, Y. Subramaniam, Does Poverty Cause Environmental Degradation? Evidence from Developing Countries, Journal of Poverty, 1-24, (2018) DOI: 10.1080/10875549.2018.1500969

7. N. Kolesnikov, N. Kolesnikova, Spatial economic effects of the use of local resources: case of cement-bonded wood fiber blocks, MATEC Web of Conferencesб 193, 03041 (2018) DOI: 10.1051/matecconf/201819303041 
8. M. Yu. Fedorova, Development of tourism in separate regions, The scientific journal of the State Commission for Academic Degrees and Titles «Regional problems of transforming the economy», 3, 36-43(2017) DOI:10.26726/2305-4484-2017-3-36-43

9. L. Yu. Piterskaya, N.A. Tlisheva, Y.N. Koshko, A. V. Piterskaya, Problems of Small, Bussiness Development In Agricultural Industry, Scientific Journal of KubSAU, 133(9), 1-18 (2017) DOI: 10.21515/1990-4665-133-111

10. V. Erokhin, W. Heijman, A. Ivolga, Sustainable Rural Development in Russia Through Diversification: The Case of the Stavropol Region, Visegrad J. Bioec. \& Sust. Dev., 1, 3, 20-25 (2014) DOI: 10.2478/vjbsd-2014-004

11. E.V. Zhirnel, L.M. Kulakova, Sustainable development and modernization of the economy of rural areas in Russia, Transactions of KarRC RAS, 3, 35-34 (2015) DOI: $10.17076 / \mathrm{reg} 82 \mathrm{i}$

12. V. Plotnikov, O. Pirogova, Intellectual capital management within the framework of the VBM concept, E3S Web of Conferences, 157, 04007 (2019), DOI https://doi.org/10.1051/e3sconf/202015704007

13. I. Aleksandrov, M. Fedorova, Digital economy and green economy: rural unemployment and territorial self-development in Russia, E3S Web of Conferences, 110, 02019 (2019), DOI https://doi.org/10.1051/e3sconf/201911002019

14. O. Rostova, S. Shirokova, N. Sokolitsyna and A. Shmeleva, Management of investment process in alternative energy projects, E3S Web of Conferences, 110, 02032 (2018). DOI:https://doi.org/10.1051/e3sconf/201911002032

15. I. Aleksandrov, M. Fedorova, New Approaches In The Strategic Development Of Rural Tourism As A Tool Of Regional Economics Development, Scientific Journal of 10 2017 Doi: 10.21515/1990-4665-134-063 